\title{
The Contributions to Primatology of Colin P. Groves (1942-2017): Corecipient of the Lifetime Achievement Award of the International Primatological Society, 2018
}

\author{
Varsha C. Pilbrow ${ }^{1}$ (D) Anthony B. Rylands ${ }^{2}$
}

Received: 5 March 2019 / Accepted: 11 March 2019 / Published online: 23 April 2019

(C) Springer Science+Business Media, LLC, part of Springer Nature 2019

Colin Peter Groves died on November 30, 2017 and became the first posthumous recipient of the Lifetime Achievement Award of the International Primatological Society in 2018 in Nairobi. With a vast publication record that spanned more than 50 years, he bolstered primate species' numbers nearly threefold, shouldering a Herculean responsibility in primatology of documenting primate diversity. This in itself is a significant achievement, so well deserving of the award, but the ripple effect of his work on research in primate biology, behavior, ecology, and conservation has been such a game changer that Colin Groves' methods and theoretical arguments are being emulated by a new generation of primatologists under the guise of the "Groves' Effect."

Local circumstances and early influences are key drivers in channeling the productivity of high achievers. It is fortunate for primatology that in Groves' case a chance book on animals gifted to him by his grandfather, and the proximity of his home town, Enfield, to London saw him studying the osteological collections of the London Natural History Museum from quite an early age. It was no surprise that he pursued a Bachelor of Science in Physical Anthropology at University College London and quickly transitioned to a PhD under the supervision of John Napier in the Unit of Primatology and Human Evolution at the Royal Free Hospital Medical School in London. Napier was the world's most eminent primatologist and primate taxonomist at the time. His suggestion that Groves undertake a taxonomic revision of gorillas by studying their skulls from British and overseas museums created a tailor-made niche for Groves for a life-long career in primatology. Collectively, museums hold many specimens, most with detailed notes on acquisition and provenance, which provide an ideal

Handling Editor: Joanna M. Setchell

Varsha C. Pilbrow

vpilbrow@unimelb.edu.au

1 Department of Anatomy and Neuroscience, Faculty of Medicine, Dentistry and Health Sciences, The University of Melbourne, Parkville, Victoria 3010, Australia

2 Primate Program, Global Wildlife Conservation, Austin, TX 78767, USA 
opportunity to study individual and population-level variability - the foundation for taxonomic classification. Groves meticulously noted all available information and metric dimensions, and indeed ventured out broadly, documenting similar detail for other groups of primates and mammals. His industriousness in data collection was matched by his speed in analyzing and publishing his results. By 1967, a year after completing his $\mathrm{PhD}$, Groves had published papers revising the taxonomy of gorillas, Gorilla gorilla, and hoolock gibbons, Hylobates hoolock, as they were then called (Groves 1967a, b, c), besides rhinoceroses, gazelles, and wild asses. Further revisions followed with similar frequency, making it clear that the work on taxonomy in primatology and mammalogy was far from complete; it had only just begun.

Groves' taxonomic research has deeply influenced our understanding of all primate families. His major taxonomic revisions of primates (Groves 1992, 2001, 2005) are still highly cited as succinct syntheses of the morphological, molecular, and phylogenetic evidence on all primate taxa. His impact on primatology is seen just as strongly through his behavioral and ecological work. His time with mountain gorillas, Gorilla beringei, in Karisoke linked his field observations on behavior and ecology with his morphological studies, strengthening his assessment of the pattern of geographic variation in gorillas. His field studies on the Tana River colobus, Piliocolobus rufomitratus, and Sulawesi macaques, Macaca spp., set the stage for more behavioral and conservation work on these primates.

Colin Groves' lifelong endeavors to identify, document, and explain the diversity of primates and other mammals resulted in significant and influential considerations regarding the parameters that define species. Groves saw clearly that mammalian taxonomy in the early twentieth century had been dominated by the Polytypic Species Concept - single species with all like forms being subspecies - a classification scheme so neat and convenient that it engendered a "taxonomic inertia"; the job was done! In the 1960s, it underpinned the Biological Species Concept (BSC), as espoused by Ernst Mayr, but Groves pointed to the BSC's inability to deal with allopatric forms, and argued cogently for the Phylogenetic Species Concept (PSC), or as he later referred to it - the diagnosability criterion - as the only concept that provides for testable hypotheses as to the validity or otherwise of the attribution of species rank. The PSC makes operational the Evolutionary Species Concept, and with the extraordinary advances and contributions of molecular genetics and genomics, his taxonomy has given us the clearest understanding we have ever had of the scope and enormity of the task of conserving the evolutionary processes and diversity of the world's primates. With his friends, the late Peter Grubb, Spartaco Gippoliti, and Christian Roos, he ended the inertia, the taxonomic impediment to the conservation of primates, and indeed of all mammals.

Conservation biology demands, above all, sound taxonomy and an understanding of the geographic distributions of the species that need protection. Colin Groves provided both. Notable and exemplary was his contribution to a Primate Taxonomy Workshop, organized by the IUCN SSC Primate Specialist Group in February 2000. The aim was a consensus taxonomy of the primates for the threatened status assessments of the IUCN Red List. Groves was the only person to contribute as author to all four of the publications that arose: taxonomic reviews of the lemurs and the Neotropical, African, and Asian primates. Colin Groves' taxonomies have been very largely adopted for the IUCN Red List of Threatened Species. 
Any celebration of Groves' scientific achievements cannot be complete without acknowledging his highly endearing personal qualities. His tremendous generosity in working with others is seen in a list of more than 150 authors as collaborators, many of them his students. His recondite understanding of primate systematics and biogeography gave him the status of unchallenged Guru, and all who knew him will have experienced the readiness, ease, and enthusiasm with which he investigated odd nomenclatural problems and tackled complex relationships among the members of the Order. Despite his formidable scientific achievements, he accepted honors with the utmost humility and often genuine surprise. His profound impact on primatology is recognized in honors such as the Margot Marsh Biodiversity Foundation's Award for Excellence in Primate Conservation, the Osman Hill Medal of the Primate Society of Great Britain and, besides, a dwarf lemur, Cheirogaleus grovesi, and a titi, Plecturocebus grovesi, named for him. Unforgettable for us, his colleagues, are his unique warmth, hospitality, and sense of humour. In Australia, his home for 44 years, Colin Groves will forever be regarded as a fair dinkum decent bloke.

Acknowledgments The authors would like to thank the organizers of the International Primatological Society for inviting us to present the Colin Groves' Lifetime Achievement Award plenary lecture in Nairobi in 2018. We also thank Prof. Joanna Setchell, editor of the International Journal of Primatology, for inviting us to write this commentary.

\section{References}

Groves, C. P. (1967a). Ecology and taxonomy of the gorilla. Nature, 213, 890-893.

Groves, C. P. (1967b). Nomenclature of the "Eastern Lowland Gorilla". Nature, 215, 1172.

Groves, C. P. (1967c). Geographic variation in the hoolock or white-browed gibbon (Hylobates hoolock Harlan, 1834). Folia Primatologica, 7, 276-283.

Groves, C. P. (1992). A theory of human and primate evolution. Oxford: Oxford Science Publications.

Groves, C. P. (2001). Primate taxonomy. Washington, DC: Smithsonian Institution Press.

Groves, C. P. (2005). Order Primates. In D. E. Wilson \& D. M. Reeder (Eds.), Mammal species of the world: A taxonomic and geographic reference (Vol. 1, 3rd ed., pp. 111-184). Baltimore, MD: Johns Hopkins University Press. 